\title{
Some Integral Type Fixed Point Theorems for Non-Self-Mappings Satisfying Generalized $(\psi, \varphi)$-Weak Contractive Conditions in Symmetric Spaces
}

\author{
Marwan Amin Kutbi, ${ }^{1}$ Mohammad Imdad, ${ }^{2}$ Sunny Chauhan, ${ }^{3}$ and Wutiphol Sintunavarat ${ }^{4}$ \\ ${ }^{1}$ Department of Mathematics, King AbdulAziz University, P.O. Box 80203, Jeddah 21589, Saudi Arabia \\ ${ }^{2}$ Department of Mathematics, Aligarh Muslim Univeristy, Aligarh 202 002, India \\ ${ }^{3}$ Near Nehru Training Centre, H. No. 274, Nai Basti B-14, Bijnor, Uttar Pradesh 246701, India \\ ${ }^{4}$ Department of Mathematics and Statistics, Faculty of Science and Technology, Thammasat University Rangsit Center, \\ Pathum Thani 12121, Thailand
}

Correspondence should be addressed to Wutiphol Sintunavarat; wutiphol@mathstat.sci.tu.ac.th

Received 10 January 2014; Accepted 10 March 2014; Published 7 April 2014

Academic Editor: Wei-Shih Du

Copyright (c) 2014 Marwan Amin Kutbi et al. This is an open access article distributed under the Creative Commons Attribution License, which permits unrestricted use, distribution, and reproduction in any medium, provided the original work is properly cited.

\begin{abstract}
The aim of this paper is to obtain some new integral type fixed point theorems for nonself weakly compatible mappings in symmetric spaces satisfying generalized $(\psi, \varphi)$-contractive conditions employing the common limit range property. We furnish some interesting examples which support our main theorems. Our results generalize and extend some recent results contained in Imdad et al. (2013) to symmetric spaces. Consequently, a host of metrical common fixed theorems are generalized and improved. In the process, we also derive a fixed point theorem for four finite families of mappings which can be utilized to derive common fixed point theorems involving any number of finite mappings.
\end{abstract}

\section{Introduction}

The celebrated Banach contraction principle is indeed the most fundamental result of metrical fixed point theory, which states that a contraction mapping of a complete metric space into itself has a unique fixed point. This theorem is very effectively utilized to establish the existence of solutions of nonlinear Volterra integral equations, Fredholm integral equations, and nonlinear integrodifferential equations in Banach spaces besides supporting the convergence of algorithms in computational mathematics. In [1], Hicks and Rhoades proved some common fixed point theorems in symmetric spaces and showed that a general probabilistic structure admits a compatible symmetric or semimetric.

The study of common fixed points for noncompatible mappings is equally interesting due to Pant [2]. Jungck [3] generalized the idea of weakly commuting pair of mappings due to Sessa [4] by introducing the notion of compatible mappings and showed that compatible pair of mappings commutes on the set of coincidence points of the involved mappings. In 1998, Jungck and Rhoades [5] introduced the notion of weakly compatible mappings in nonmetric spaces. For more details on systematic comparisons and illustrations of these described notions, we refer to Singh and Tomar [6] and Murthy [7]. Afterwards, Al-Thagafi and Shahzad [8] introduced an even weaker notion which they called occasionally weak compatibility. Many authors (see, e.g., [9-12]) used this notion to obtain common fixed point results. Recently, Đorić et al. [13] showed that, for single-valued mappings, the condition of occasionally weak compatibility reduces to weak compatibility in the case of a unique point of coincidence (and a unique common fixed point) of the given mappings. However, for hybrid pairs of maps, this is not the case.

On the other hand, in 2002, Aamri and El Moutawakil [14] introduced the notion of property (E.A) which is a special case of tangential property due to Sastry and Krishna Murthy [15]. Later on, Liu et al. [16] initiated the notion of 
common property (E.A) for hybrid pairs of mappings which contained property (E.A). In this continuation, Imdad et al. [17] and Soliman et al. [18] extended the results of Sastry and Krishna Murthy [15] and Pant [19] to symmetric spaces by utilizing the weak compatible property with common property (E.A). Since the notions of property (E.A) and common property (E.A) always require the completeness (or closedness) of underlying subspaces for the existence of common fixed point, hence Sintunavarat and Kumam [20] coined the idea of "common limit range property" which relaxes the requirement of completeness (or closedness) of the underlying subspace. Afterward, Imdad et al. [21] extended the notion of common limit range property to two pairs of self-mappings and proved some fixed point theorems in Menger and metric spaces. Most recently, Karapınar et al. [22] utilized the notion of common limit range property and showed that the new notion buys certain typical conditions utilized by Pant [19] up to a pair of mappings on the cast of a relatively more natural absorbing property due to Gopal et al. [23].

The concept of weak contraction was introduced by Alber and Guerre-Delabriere [24] in 1997 wherein authors introduced the following notion for mappings defined on a Hilbert space $H$.

Consider the following set of real functions:

$$
\begin{aligned}
& \Phi=\{\varphi:[0,+\infty) \longrightarrow[0,+\infty): \varphi \text { is lower } \\
&\text { semi-continuous and } \left.\varphi^{-1}(\{0\})=\{0\}\right\}
\end{aligned}
$$

A mapping $T: X \rightarrow X$ is called a $\varphi$-weak contraction if there exists a function $\varphi \in \Phi$ such that

$$
d(T x, T y) \leq d(x, y)-\varphi(d(x, y)), \quad \forall x, y \in X
$$

Alber and Guerre-Delabriere [24] also showed that each $\varphi$-weak contraction on a Hilbert space has a unique fixed point. Thereafter, Rhoades [25] showed that the results contained in [24] are also valid for any Banach space. In particular, he generalized the Banach contraction principle which follows in case one chooses $\varphi(t)=(1-k) t$.

In 2002, Branciari [26] firstly studied the integral analogue of Banach's contraction principle. Some interesting results can be easily seen in [27-32]. Most recently, Vetro et al. [33] proved some integral type fixed point results for mappings in metric spaces employing common limit range property. Zhang and Song [34] proved a common fixed point theorem for two mappings by using $\varphi$-weak contraction. This result was extended by Đorić [35] and Dutta and Choudhury [36] to a pair of $(\psi, \varphi)$-weak contractive mappings. However, the main fixed point theorem for a self-mapping satisfying $(\psi, \varphi)$-weak contractive condition contained in Dutta and Choudhury [36] is given below, but, before that, we consider the following set of real functions:

$$
\begin{gathered}
\Psi=\{\psi:[0,+\infty) \longrightarrow[0,+\infty): \psi \text { is continuous } \\
\text { nondecreasing and } \left.\psi^{-1}(\{0\})=\{0\}\right\} .
\end{gathered}
$$

Theorem 1. Let $(X, d)$ be a complete metric space and let $T$ : $X \rightarrow X$ be a self-mapping satisfying

$$
\psi(d(T x, T y)) \leq \psi(d(x, y))-\varphi(d(x, y))
$$

for some $\psi \in \Psi$ and $\varphi \in \Phi$ and all $x, y \in X$. Then $T$ has $a$ unique fixed point in $X$.

The object of this paper is to prove some integral type common fixed point theorems for two pairs of nonself weakly compatible mappings satisfying generalized $(\psi, \varphi)$ contractive conditions by using the common limit range property in symmetric spaces. We give some illustrative examples to highlight the superiority of our results over several results existing in the literature. As an extension of our main result, we state some fixed point theorems for six mappings and four finite families of mappings in symmetric spaces by using the notion of the pairwise commuting mappings which is studied by Imdad et al. [37].

\section{Preliminaries}

A common fixed point result generally involves conditions on commutativity, continuity, and contraction along with a suitable condition on the containment of range of one mapping into the range of the other. Hence, one is always required to improve one or more of these conditions in order to prove a new common fixed point theorem. It can be observed that in the case of two mappings $A, S: X \rightarrow X$, where $(X, d)$ is metric space (or symmetric space), one can consider the following classes of mappings for the existence and uniqueness of common fixed points:

$$
d(A x, A y) \leq F(m(x, y))
$$

where $F$ is some function and $m(x, y)$ is the maximum of one of the sets. Thus,

$$
\begin{aligned}
M_{A, S}^{5}(x, y)= & \{d(S x, S y), d(S x, A x), d(S y, A y), \\
& d(S x, A y), d(S y, A x)\}, \\
M_{A, S}^{4}(x, y)=\{d(S x, S y), d(S x, A x), d(S y, A y), & \left.\frac{1}{2}(d(S x, A y)+d(S y, A x))\right\}, \\
M_{A, S}^{3}(x, y)=\left\{d(S x, S y), \frac{1}{2}(d(S x, A x)+d(S y, A y)),\right. & \left.\frac{1}{2}(d(S x, A y)+d(S y, A x))\right\} .
\end{aligned}
$$

A further possible generalization is to consider four mappings instead of two and ascertain analogous common fixed point theorems. In the case of four mappings $A, B, S, T$ : 
$X \rightarrow X$, where $(X, d)$ is metric space (or symmetric space), the corresponding sets take the form

$$
\begin{aligned}
& M_{A, B, S, T}^{5}(x, y)=\{ d(S x, T y), d(S x, A x), d(T y, B y), \\
&d(S x, B y), d(T y, A x)\}, \\
& M_{A, B, S, T}^{4}(x, y)=\{d(S x, T y), d(S x, A x), d(T y, B y),\left.\frac{1}{2}(d(S x, B y)+d(T y, A x))\right\}, \\
& M_{A, B, S, T}^{3}(x, y)=\left\{d(S x, T y), \frac{1}{2}(d(S x, A x)+d(T y, B y)),\right. \\
&\left.\frac{1}{2}(d(S x, B y)+d(T y, A x))\right\} .
\end{aligned}
$$

In this case (5) is usually replaced by

$$
d(A x, B y) \leq F(m(x, y)),
$$

where $m(x, y)$ is the maximum of one of the $M$-sets.

Similarly, we can define the $M$-sets for six mappings $A, B, H, R, S, T: X \rightarrow X$, where $(X, d)$ is metric space (or symmetric space), as

$$
\begin{aligned}
& M_{A, B, H, R, S, T}^{5}(x, y)=\{ d(S R x, T H y), d(S R x, A x), \\
& d(T H y, B y), \\
&d(S R x, B y), d(T H y, A x)\}, \\
& M_{A, B, H, R, S, T}^{4}(x, y)=\{d(S R x, T H y), \\
& \frac{1}{2}(d(S R x, A x), d(T H y, B y), \\
& M_{A, B, H, R, S, T}^{3}(x, y)=\{d(S R x, T H y), \frac{1}{2}(d(S R x, A x)+d(T H y, B y)), \\
&\left.\frac{1}{2}(d(S R x, B y)+d(T H y, A x))\right\},
\end{aligned}
$$

and the contractive condition is again in the form (8).

By using different arguments of control functions, Radenović et al. [38] proved some common fixed point results for two and three mappings by using $(\psi, \varphi)$-weak contractive conditions and improved several known metrical fixed point theorems. Motivated by these results, we prove some common fixed point theorems for two pairs of weakly compatible mappings with common limit range property satisfying generalized $(\psi, \varphi)$-weak contractive conditions. Many known fixed point results are improved, especially the ones proved in [38] and also contained in the references cited therein. We also obtain a fixed point theorem for four finite families of self-mappings. Some related results are also derived besides furnishing illustrative examples.

The following definitions and results will be needed in the sequel.

A symmetric on a set $X$ is a function $d: X \times X \rightarrow[0, \infty)$ satisfying the following conditions:

(1) $d(x, y)=0$ if and only if $x=y$ for $x, y \in X$,

(2) $d(x, y)=d(y, x)$ for all $x, y \in X$.

Let $d$ be a symmetric on a set $X$. For $x \in X$ and $\epsilon>0$, let $\mathscr{B}(x, \epsilon)=\{y \in X: d(x, y)<\epsilon\}$. A topology $\tau(d)$ on $X$ is defined as follows: $U \in \tau(d)$ if and only if, for each $x \in U$, there exists an $\epsilon>0$ such that $\mathscr{B}(x, \epsilon) \subset U$. A subset $S$ of $X$ is a neighbourhood of $x \in X$ if there exists $U \in \tau(d)$ such that $x \in U \subset S$. A symmetric $d$ is a semimetric if, for each $x \in X$ and each $\epsilon>0, \mathscr{B}(x, \epsilon)$ is a neighbourhood of $x$ in the topology $\tau(d)$. A symmetric (resp., semimetric) space $(X, d)$ is a topological space whose topology $\tau(d)$ on $X$ is induced by symmetric (resp., semimetric) $d$. The difference of a symmetric and a metric comes from the triangle inequality. Since a symmetric space is not essentially Hausdorff, therefore in order to prove fixed point theorems some additional axioms are required. The following axioms, which are available in Wilson [39], Aliouche [40], and Imdad et al. [17], are relevant to this presentation.

From now on symmetric space will be denoted by $(X, d)$ whereas a nonempty arbitrary set will be denoted by $Y$.

$\left(W_{3}\right)$ Given $\left\{x_{n}\right\}, x$, and $y$ in $X, \lim _{n \rightarrow \infty} d\left(x_{n}, x\right)=0$ and $\lim _{n \rightarrow \infty} d\left(x_{n}, y\right)=0$ imply $x=y$ [39].

$\left(W_{4}\right)$ Given $\left\{x_{n}\right\},\left\{y_{n}\right\}$, and $x$ in $X, \lim _{n \rightarrow \infty} d\left(x_{n}, x\right)=0$ and $\lim _{n \rightarrow \infty} d\left(x_{n}, y_{n}\right)=0$ imply $\lim _{n \rightarrow \infty} d\left(y_{n}, x\right)=0$ [39].

(HE) Given $\left\{x_{n}\right\},\left\{y_{n}\right\}$, and $x$ in $X, \lim _{n \rightarrow \infty} d\left(x_{n}, x\right)=0$ and $\lim _{n \rightarrow \infty} d\left(y_{n}, x\right)=0$ imply $\lim _{n \rightarrow \infty} d\left(x_{n}, y_{n}\right)=0$ [40].

(1C) A symmetric $d$ is said to be 1-continuous if $\lim _{n \rightarrow \infty} d\left(x_{n}, x\right)=0$ implies $\lim _{n \rightarrow \infty} d\left(x_{n}, y\right)=$ $d(x, y)$, where $\left\{x_{n}\right\}$ is a sequence in $X$ and $x, y \in X$ [41].

(CC) A symmetric $d$ is said to be continuous if $\lim _{n \rightarrow \infty} d\left(x_{n}, x\right)=0$ and $\lim _{n \rightarrow \infty} d\left(y_{n}, y\right)=0$ imply $\lim _{n \rightarrow \infty} d\left(x_{n}, y_{n}\right)=d(x, y)$, where $\left\{x_{n}\right\}$ and $\left\{y_{n}\right\}$ are sequences in $X$ and $x, y \in X[41]$.

Here, it is observed that $(C C) \Rightarrow(1 C),\left(W_{4}\right) \Rightarrow\left(W_{3}\right)$, and $(1 C) \Rightarrow\left(W_{3}\right)$ but the converse implications are not true. In general, all other possible implications amongst $\left(W_{3}\right)$, $(1 C)$, and $(H E)$ are not true. For detailed description, we refer an interesting note of Cho et al. [42] which contained some illustrative examples. However, (CC) implies all the remaining four conditions, namely, $\left(W_{3}\right),\left(W_{4}\right),(H E)$, and $(1 C)$. Employing these axioms, several authors proved common fixed point theorems in the framework of symmetric spaces (see $[22,43-48])$. 
Definition 2. Let $(A, S)$ be a pair of self-mappings defined on a nonempty set $X$ equipped with a symmetric $d$. Then the mappings $A$ and $S$ are said to be

(1) commuting if $A S x=S A x$ for all $x \in X$,

(2) compatible [3] if $\lim _{n \rightarrow \infty} d\left(A S x_{n}, S A x_{n}\right)=0$ for each sequence $\left\{x_{n}\right\}$ in $Y$ such that $\lim _{n \rightarrow \infty} A x_{n}=$ $\lim _{n \rightarrow \infty} S x_{n}$,

(3) noncompatible [2] if there exists a sequence $\left\{x_{n}\right\}$ in $X$ such that $\lim _{n \rightarrow \infty} A x_{n}=\lim _{n \rightarrow \infty} S x_{n}$ but $\lim _{n \rightarrow \infty} d\left(A S x_{n}, S A x_{n}\right)$ is either nonzero or nonexistent,

(4) weakly compatible [5] if they commute at their coincidence points, that is, $A S x=S A x$ whenever $A x=S x$, for some $x \in X$,

(5) satisfied the property (E.A) [14] if there exists a sequence $\left\{x_{n}\right\}$ in $X$ such that $\lim _{n \rightarrow \infty} A x_{n}=$ $\lim _{n \rightarrow \infty} S x_{n}=z$, for some $z \in X$.

Any pair of compatible as well as noncompatible selfmappings satisfies the property (E.A) but a pair of mappings satisfying the property (E.A) needs not be noncompatible.

Definition 3 (see [16]). Let $Y$ be an arbitrary set and let $X$ be a nonempty set equipped with symmetric $d$. Then the pairs $(A, S)$ and $(B, T)$ of mappings from $Y$ into $X$ are said to share the common property (E.A), if there exist two sequences $\left\{x_{n}\right\}$ and $\left\{y_{n}\right\}$ in $Y$ such that

$$
\lim _{n \rightarrow \infty} A x_{n}=\lim _{n \rightarrow \infty} S x_{n}=\lim _{n \rightarrow \infty} B y_{n}=\lim _{n \rightarrow \infty} T y_{n}=z,
$$

for some $z \in X$.

Definition 4 (see [20]). Let $Y$ be an arbitrary set and let $X$ be a nonempty set equipped with symmetric $d$. Then the pair $(A, S)$ of mappings from $Y$ into $X$ is said to have the common limit range property with respect to the mapping $S$ (denoted by $\left.\left(\operatorname{CLR}_{S}\right)\right)$ if there exists a sequence $\left\{x_{n}\right\}$ in $Y$ such that

$$
\lim _{n \rightarrow \infty} A x_{n}=\lim _{n \rightarrow \infty} S x_{n}=z
$$

where $z \in S(Y)$.

Definition 5 (see [21]). Let $Y$ be an arbitrary set and let $X$ be a nonempty set equipped with symmetric $d$. Then the pairs $(A, S)$ and $(B, T)$ of mappings from $Y$ into $X$ are said to have the common limit range property with respect to mappings $S$ and $T$, denoted by $\left(\operatorname{CLR}_{S T}\right)$, if there exist two sequences $\left\{x_{n}\right\}$ and $\left\{y_{n}\right\}$ in $Y$ such that

$$
\lim _{n \rightarrow \infty} A x_{n}=\lim _{n \rightarrow \infty} S x_{n}=\lim _{n \rightarrow \infty} B y_{n}=\lim _{n \rightarrow \infty} T y_{n}=z,
$$

where $z \in S(Y) \cap T(Y)$.

Remark 6. It is clear that $\left(\mathrm{CLR}_{S T}\right)$ property implies the common property (E.A) but the converse is not true (see [49, Example 1]).

Definition 7 (see [37]). Two families of self-mappings $\left\{A_{i}\right\}_{i=1}^{m}$ and $\left\{S_{k}\right\}_{k=1}^{n}$ are said to be pairwise commuting if
(1) $A_{i} A_{j}=A_{j} A_{i}$ for all $i, j \in\{1,2, \ldots, m\}$,

(2) $S_{k} S_{l}=S_{l} S_{k}$ for all $k, l \in\{1,2, \ldots, n\}$,

(3) $A_{i} S_{k}=S_{k} A_{i}$ for all $i \in\{1,2, \ldots, m\}$ and $k \in$ $\{1,2, \ldots, n\}$.

\section{Results}

Now, we state and prove our main results for four mappings employing the common limit range property in symmetric spaces. Firstly, we prove the following lemma.

Lemma 8. Let $(X, d)$ be a symmetric space wherein d satisfies the conditions (CC) whereas $Y$ is an arbitrary nonempty set with $A, B, S$ and $T: Y \rightarrow X$. Suppose that

(1) the pair $(A, S)$ (or $(B, T))$ satisfies the $\left(C L R_{S}\right)$ (or $\left.\left(C L R_{T}\right)\right)$ property,

(2) $A(Y) \subset T(Y)($ or $B(Y) \subset S(Y))$,

(3) $T(Y)($ or $S(Y))$ is a closed subset of $X$,

(4) $\left\{B y_{n}\right\}$ converges for every sequence $\left\{y_{n}\right\}$ in $Y$ whenever $\left\{T y_{n}\right\}$ converges (or $\left\{A x_{n}\right\}$ converges for every sequence $\left\{x_{n}\right\}$ in $Y$ whenever $\left\{S x_{n}\right\}$ converges),

(5) there exist $\varphi \in \Phi$ and $\psi \in \Psi$ such that for all $x, y \in Y$, we have

$$
\begin{aligned}
& \psi\left(\int_{0}^{d(A x, B y)} \phi(t) d t\right) \\
& \quad \leq \psi\left(\int_{0}^{m(x, y)} \phi(t) d t\right)-\varphi\left(\int_{0}^{m(x, y)} \phi(t) d t\right),
\end{aligned}
$$

where

$$
m(x, y)=\max M_{A, B, S, T}^{5}(x, y)
$$

and $\phi:[0,+\infty) \rightarrow[0,+\infty)$ is a Lebesgue-integrable mapping which is summable and nonnegative such that

$$
\int_{0}^{\epsilon} \phi(t) d t>0
$$

for all $\epsilon>0$.

Then the pairs $(A, S)$ and $(B, T)$ satisfy the $\left(C L R_{S T}\right)$ property.

Proof. First, we show that the conclusion of this theorem holds for first case. Since the pair $(A, S)$ enjoys the $\left(\mathrm{CLR}_{S}\right)$ property; therefore there exists a sequence $\left\{x_{n}\right\}$ in $Y$ such that

$$
\lim _{n \rightarrow \infty} A x_{n}=\lim _{n \rightarrow \infty} S x_{n}=z,
$$

where $z \in S(Y)$. Since $A(Y) \subset T(Y)$, hence for each sequence $\left\{x_{n}\right\}$ there exists a sequence $\left\{y_{n}\right\}$ in $Y$ such that $A x_{n}=T y_{n}$. Therefore, by closedness of $T(Y)$,

$$
\lim _{n \rightarrow \infty} T y_{n}=\lim _{n \rightarrow \infty} A x_{n}=z,
$$

for $z \in T(Y)$ and in all $z \in S(Y) \cap T(Y)$. Thus, in all, we have $A x_{n} \rightarrow z, S x_{n} \rightarrow z$ and $T y_{n} \rightarrow z$ as $n \rightarrow \infty$. Since by 
(4), $\left\{B y_{n}\right\}$ converges, in all we need to show that $\left\{B y_{n}\right\} \rightarrow z$ as $n \rightarrow \infty$. Assume this contrary, we get $B y_{n} \rightarrow t(\neq z)$ as $n \rightarrow \infty$. Now, using inequality (13) with $=x_{n}, y=y_{n}$, we have

$$
\begin{aligned}
& \psi\left(\int_{0}^{d\left(A x_{n}, B y_{n}\right)} \phi(t) d t\right) \\
& \quad \leq \psi\left(\int_{0}^{m\left(x_{n}, y_{n}\right)} \phi(t) d t\right)-\varphi\left(\int_{0}^{m\left(x_{n}, y_{n}\right)} \phi(t) d t\right),
\end{aligned}
$$

where

$$
\begin{gathered}
m\left(x_{n}, y_{n}\right)=\max \left\{d\left(S x_{n}, T y_{n}\right), d\left(S x_{n}, A x_{n}\right), d\left(T y_{n}, B y_{n}\right),\right. \\
\left.d\left(S x_{n}, B y_{n}\right), d\left(T y_{n}, A x_{n}\right)\right\} .
\end{gathered}
$$

Taking limit as $n \rightarrow \infty$ and using property $(C C)$ in inequality (18), we get

$$
\begin{aligned}
\lim _{n \rightarrow \infty} \psi & \left(\int_{0}^{d\left(A x_{n}, B y_{n}\right)} \phi(t) d t\right) \\
\leq & \lim _{n \rightarrow \infty} \psi\left(\int_{0}^{m\left(x_{n}, y_{n}\right)} \phi(t) d t\right) \\
& -\lim _{n \rightarrow \infty} \varphi\left(\int_{0}^{m\left(x_{n}, y_{n}\right)} \phi(t) d t\right) ;
\end{aligned}
$$

that is,

$$
\begin{aligned}
\psi\left(\int_{0}^{d(z, t)} \phi(t) d t\right) \\
=\psi\left(\lim _{n \rightarrow \infty} \int_{0}^{d\left(A x_{n}, B y_{n}\right)} \phi(t) d t\right) \\
\leq \psi\left(\lim _{n \rightarrow \infty} \int_{0}^{m\left(x_{n}, y_{n}\right)} \phi(t) d t\right) \\
\quad-\varphi\left(\lim _{n \rightarrow \infty} \int_{0}^{m\left(x_{n}, y_{n}\right)} \phi(t) d t\right),
\end{aligned}
$$

where

$$
\begin{aligned}
\lim _{n \rightarrow \infty} m\left(x_{n}, y_{n}\right) \\
\quad=\max \{d(z, z), d(z, z), d(z, t), d(z, t), d(z, z)\} \\
\quad=\max \{0,0, d(z, t), d(z, t), 0\} \\
\quad=d(z, t) .
\end{aligned}
$$

Hence inequality (21) implies

$$
\begin{aligned}
& \psi\left(\int_{0}^{d(z, t)} \phi(t) d t\right) \\
& \quad \leq \psi\left(\int_{0}^{d(z, t)} \phi(t) d t\right)-\varphi\left(\int_{0}^{d(z, t)} \phi(t) d t\right) ;
\end{aligned}
$$

that is, $\varphi\left(\int_{0}^{d(z, t)} \phi(t) d t\right) \leq 0$ and so $\varphi\left(\int_{0}^{d(z, t)} \phi(t) d t\right)=0$ and, by the property of the function $\varphi$, we have $d(z, t)=0$ or equivalently $z=t$, which contradicts the hypothesis $t \neq z$. Hence both the pairs $(A, S)$ and $(B, T)$ satisfy the $\left(\mathrm{CLR}_{S T}\right)$ property.

In the second case, it similar to the first case. So, in order to avoid repetition, the details of the proof are omitted. This completes the proof.

Theorem 9. Let $(X, d)$ be a symmetric space whereind satisfies the conditions $(1 C)$ and $(H E)$ whereas $Y$ is an arbitrary nonempty set with $A, B, S, T: Y \rightarrow X$, which satisfy the inequalities (13) and (15) of Lemma 8. Suppose that the pairs $(A, S)$ and $(B, T)$ satisfy the $\left(C L R_{S T}\right)$ property. Then $(A, S)$ and $(B, T)$ have a coincidence point each. Moreover, if $Y=X$, then $A, B, S$ and $T$ have a unique common fixed point provided both the pairs $(A, S)$ and $(B, T)$ are weakly compatible.

Proof. Since the pairs $(A, S)$ and $(B, T)$ enjoy the $\left(\mathrm{CLR}_{S T}\right)$ property, there exist two sequences $\left\{x_{n}\right\}$ and $\left\{y_{n}\right\}$ in $Y$ such that

$$
\begin{aligned}
\lim _{n \rightarrow \infty} d\left(A x_{n}, z\right) & =\lim _{n \rightarrow \infty} d\left(S x_{n}, z\right)=\lim _{n \rightarrow \infty} d\left(B y_{n}, z\right) \\
& =\lim _{n \rightarrow \infty} d\left(T y_{n}, z\right)=0,
\end{aligned}
$$

where $z \in S(Y) \cap T(Y)$. It follows from $z \in S(Y)$ that there exists a point $w \in Y$ such that $S w=z$. We assert that $A w=z$. If not, then, using inequality (13) with $x=w$ and $y=y_{n}$, one obtains

$$
\begin{aligned}
& \psi\left(\int_{0}^{d\left(A w, B y_{n}\right)} \phi(t) d t\right) \\
& \quad \leq \psi\left(\int_{0}^{m\left(w, y_{n}\right)} \phi(t) d t\right)-\varphi\left(\int_{0}^{m\left(w, y_{n}\right)} \phi(t) d t\right),
\end{aligned}
$$

where

$$
\begin{gathered}
m\left(w, y_{n}\right)=\max \left\{d\left(S w, T y_{n}\right), d(S w, A w), d\left(T y_{n}, B y_{n}\right),\right. \\
\left.d\left(S w, B y_{n}\right), d\left(T y_{n}, A w\right)\right\}
\end{gathered}
$$

Taking limit as $n \rightarrow \infty$ and using properties $(1 C)$ and $(H E)$ in inequality (25), one obtains

$$
\begin{aligned}
\lim _{n \rightarrow \infty} \psi\left(\int_{0}^{d\left(A w, B y_{n}\right)} \phi(t) d t\right) \\
\leq \lim _{n \rightarrow \infty} \psi\left(\int_{0}^{m\left(w, y_{n}\right)} \phi(t) d t\right) \\
\quad-\lim _{n \rightarrow \infty} \varphi\left(\int_{0}^{m\left(w, y_{n}\right)} \phi(t) d t\right) ;
\end{aligned}
$$


that is,

$$
\begin{aligned}
\psi\left(\int_{0}^{d(A w, z)} \phi(t) d t\right) \\
=\psi\left(\lim _{n \rightarrow \infty} \int_{0}^{d\left(A w, B y_{n}\right)} \phi(t) d t\right) \\
\leq \psi\left(\lim _{n \rightarrow \infty} \int_{0}^{m\left(w, y_{n}\right)} \phi(t) d t\right) \\
\quad-\varphi\left(\lim _{n \rightarrow \infty} \int_{0}^{m\left(w, y_{n}\right)} \phi(t) d t\right),
\end{aligned}
$$

where

$$
\begin{aligned}
\lim _{n \rightarrow \infty} & m\left(w, y_{n}\right) \\
& =\max \{d(z, z), d(z, A w), d(z, z), d(z, z), d(z, A w)\} \\
& =\max \{0, d(z, A w), 0,0, d(z, A w)\} \\
& =d(z, A w)
\end{aligned}
$$

From inequality (28), one gets

$$
\begin{aligned}
& \psi\left(\int_{0}^{d(A w, z)} \phi(t) d t\right) \\
& \quad \leq \psi\left(\int_{0}^{d(A w, z)} \phi(t)\right)-\varphi\left(\int_{0}^{d(A w, z)} \phi(t)\right),
\end{aligned}
$$

so that $\varphi\left(\int_{0}^{d(A w, z)} \phi(t) d t\right)=0$; that is, $d(A w, z)=0$. Hence $A w=S w=z$ which shows that $w$ is a coincidence point of the pair $(A, S)$.

Also $z \in T(Y)$, there exists a point $v \in Y$ such that $T v=z$. We assert that $B v=z$. If not, then, using inequality (13) with $x=w, y=v$, we have

$$
\begin{aligned}
& \psi\left(\int_{0}^{d(z, B v)} \phi(t) d t\right) \\
& \quad=\psi\left(\int_{0}^{d(A w, B v)} \phi(t) d t\right) \\
& \quad \leq \psi\left(\int_{0}^{m(w, v)} \phi(t) d t\right)-\varphi\left(\int_{0}^{m(w, v)} \phi(t) d t\right),
\end{aligned}
$$

where

$$
\begin{aligned}
m(w, v) & \\
= & \max \{d(S w, T v), d(S w, A w), d(T v, B v), \\
& d(S w, B v), d(T v, A w)\} \\
= & \max \{d(z, z), d(z, z), d(z, B v), d(z, B v), d(z, z)\} \\
= & \max \{0,0, d(z, B v), d(z, B v), 0\} \\
= & d(z, B v) .
\end{aligned}
$$

Hence inequality (31) implies

$$
\begin{aligned}
& \psi\left(\int_{0}^{d(z, B v)} \phi(t) d t\right) \\
& \quad \leq \psi\left(\int_{0}^{d(z, B v)} \phi(t) d t\right)-\varphi\left(\int_{0}^{d(z, B v)} \phi(t) d t\right),
\end{aligned}
$$

so that $\varphi\left(\int_{0}^{d(z, B v)} \phi(t) d t\right)=0$; that is, $d(z, B v)=0$. Therefore $z=B v=T v$ which shows that $v$ is a coincidence point of the pair $(B, T)$.

Consider $Y=X$. Since the pair $(A, S)$ is weakly compatible and $A w=S w$, hence $A z=A S w=S A w=S z$. Now we assert that $z$ is a common fixed point of the pair $(A, S)$. To accomplish this, using inequality (13) with $x=z$ and $y=v$, one gets

$$
\begin{aligned}
& \psi\left(\int_{0}^{d(A z, z)} \phi(t) d t\right) \\
& \quad=\psi\left(\int_{0}^{d(A z, B v)} \phi(t) d t\right) \\
& \quad \leq \psi\left(\int_{0}^{m(z, v)} \phi(t) d t\right)-\varphi\left(\int_{0}^{m(z, v)} \phi(t) d t\right),
\end{aligned}
$$

where

$$
\begin{gathered}
m(z, v) \\
=\max \{d(S z, T v), d(S z, A z), d(T v, B v), \\
\quad d(S z, B v), d(T v, A z)\} \\
=\max \{d(A z, z), d(A z, A z), d(z, z), \\
\quad d(A z, z), d(z, A z)\} \\
=d(A z, z) .
\end{gathered}
$$

From inequality (34), we have

$$
\begin{aligned}
& \psi\left(\int_{0}^{d(A z, z)} \phi(t) d t\right) \\
& \quad \leq \psi\left(\int_{0}^{d(A z, z)} \phi(t) d t\right)-\varphi\left(\int_{0}^{d(A z, z)} \phi(t) d t\right),
\end{aligned}
$$

so that $\varphi\left(\int_{0}^{d(A z, z)} \phi(t) d t\right)=0$; that is, $d(A z, z)=0$. Hence we have $A z=z=S z$ which shows that $z$ is a common fixed point of the pair $(A, S)$.

Also the pair $(B, T)$ is weakly compatible and $B v=T v$; hence $B z=B T v=T B v=T z$. Using inequality (13) with $x=w$ and $y=z$, we have

$$
\begin{aligned}
& \psi\left(\int_{0}^{d(z, B z)} \phi(t) d t\right) \\
& \quad=\psi\left(\int_{0}^{d(A w, B z)} \phi(t) d t\right) \\
& \quad \leq \psi\left(\int_{0}^{m(w, z)} \phi(t) d t\right)-\varphi\left(\int_{0}^{m(w, z)} \phi(t) d t\right),
\end{aligned}
$$


where

$$
\begin{gathered}
m(w, z)=\max \{d(S w, T z), d(S w, A w), d(T z, B z), \\
d(S w, B z), d(T z, A w)\} \\
=\max \{d(z, B z), d(z, z), d(B z, B z), \\
\quad d(z, B z), d(B z, z)\} \\
=d(z, B z) .
\end{gathered}
$$

Hence inequality (37) implies

$$
\begin{aligned}
& \psi\left(\int_{0}^{d(z, B z)} \phi(t) d t\right) \\
& \quad \leq \psi\left(\int_{0}^{d(z, B z)} \phi(t) d t\right)-\varphi\left(\int_{0}^{d(z, B z)} \phi(t) d t\right),
\end{aligned}
$$

so that $\varphi\left(\int_{0}^{d(z, B z)} \phi(t) d t\right)=0$; that is, $d(z, B z)=0$. Therefore, $B z=z=T z$ which shows that $z$ is a common fixed point of the pair $(B, T)$. Hence $z$ is a common fixed point of the pairs $(A, S)$ and $(B, T)$. Uniqueness of common fixed point is an easy consequence of the inequality (13). This concludes the proof.

Now, we furnish an illustrative example which demonstrates the validity of the hypotheses and degree of generality of Theorem 9.

Example 10. Consider $X=Y=[2,11)$ equipped with the symmetric $d(x, y)=(x-y)^{2}$ for all $x, y \in X$, which also satisfies $(1 C)$ and $(H E)$. Define the mappings $A, B, S$ and $T$ by

$$
\begin{aligned}
& A x= \begin{cases}2, & \text { if } x \in\{2\} \cup(5,11), \\
5, & \text { if } x \in(2,5] ;\end{cases} \\
& B x= \begin{cases}2, & \text { if } x \in\{2\} \cup(5,11), \\
4, & \text { if } x \in(2,5] ;\end{cases} \\
& S x= \begin{cases}2, & \text { if } x=2, \\
6, & \text { if } x \in(2,5] ; \\
\frac{3 x+1}{8}, & \text { if } x \in(5,11) ;\end{cases} \\
& T x= \begin{cases}2, & \text { if } x=2, \\
8, & \text { if } x \in(2,5] ; \\
x-3, & \text { if } x \in(5,11) .\end{cases}
\end{aligned}
$$

Then $A(X)=\{2,5\}, B(X)=\{2,4\}, T(X)=[2,8]$ and $S(X)=$ $[2,17 / 4) \cup\{6\}$. Now, consider the sequences $\left\{x_{n}\right\}=\{5+1 / n\}$ and $\left\{y_{n}\right\}=\{2\}$. Then

$$
\begin{aligned}
\lim _{n \rightarrow \infty} A x_{n} & =\lim _{n \rightarrow \infty} S x_{n}=\lim _{n \rightarrow \infty} B y_{n}=\lim _{n \rightarrow \infty} T y_{n} \\
& =2 \in S(X) \cap T(X) ;
\end{aligned}
$$

that is, both the pairs $(A, S)$ and $(B, T)$ satisfy the $\left(\operatorname{CLR}_{S T}\right)$ property.
Let Lebesgue-integrable $\phi:[0,+\infty) \rightarrow[0,+\infty)$ defined by $\phi(t)=e^{t}$. Take $\psi \in \Psi$ and $\varphi \in \Phi$ given by $\psi(t)=2 t$ and $\varphi(t)=(2 / 7) t$. In order to check the contractive condition (13), consider the following nine cases:

(i) $x=y=2$,

(ii) $x=2, y \in(2,5]$,

(iii) $x=2, y \in(5,11)$,

(iv) $x \in(2,5], y=2$,

(v) $x, y \in(2,5]$,

(vi) $x \in(2,5], y \in(5,11)$,

(vii) $x \in(5,11), y=2$,

(viii) $x \in(5,11), y \in(2,5]$,

(ix) $x, y \in(5,11)$.

In the cases (i), (iii), (vii), and (ix), we get that $d(A x, B y)=$ 0 and (13) is trivially satisfied.

In the cases (ii) and (viii), we have $d(A x, B y)=4$ and $m(x, y)=36$. Now we have

$$
\begin{aligned}
\psi\left(\int_{0}^{d(A x, B y)} \phi(t) d t\right) & =\psi\left(\int_{0}^{4} e^{t} d t\right) \\
& =\psi\left(e^{4}-1\right) \\
& =2\left(e^{4}-1\right) \\
& \leq \frac{12}{7}\left(e^{36}-1\right) \\
& =2\left(e^{36}-1\right)-\frac{2}{7}\left(e^{36}-1\right) \\
& =\psi\left(\int_{0}^{36} e^{t} d t\right)-\varphi\left(\int_{0}^{36} e^{t} d t\right) \\
& =\psi\left(\int_{0}^{m(x, y)} \phi(t) d t\right) \\
& -\varphi\left(\int_{0}^{m(x, y)} \phi(t) d t\right) .
\end{aligned}
$$

Therefore, we get the fact that (13) holds. 
In the case (iv), we get $d(A x, B y)=9$ and $m(x, y)=16$. Now we have

$$
\begin{aligned}
\psi\left(\int_{0}^{d(A x, B y)} \phi(t) d t\right) & =\psi\left(\int_{0}^{9} e^{t} d t\right) \\
& =\psi\left(e^{9}-1\right) \\
& =2\left(e^{9}-1\right) \\
& \leq \frac{12}{7}\left(e^{16}-1\right) \\
& =2\left(e^{16}-1\right)-\frac{2}{7}\left(e^{16}-1\right) \\
& =\psi\left(\int_{0}^{16} e^{t} d t\right)-\varphi\left(\int_{0}^{16} e^{t} d t\right) \\
& =\psi\left(\int_{0}^{m(x, y)} \phi(t) d t\right) \\
& -\varphi\left(\int_{0}^{m(x, y)} \phi(t) d t\right) .
\end{aligned}
$$

This implies that (13) holds.

In the case (vi), we have $d(A x, B y)=9$ and $d(S x, B y)=$ 16. Now we have

$$
\begin{aligned}
\psi\left(\int_{0}^{d(A x, B y)} \phi(t) d t\right)= & \psi\left(\int_{0}^{9} e^{t} d t\right) \\
& =\psi\left(e^{9}-1\right) \\
& =2\left(e^{9}-1\right) \\
& \leq \frac{12}{7}\left(e^{16}-1\right) \\
& =\frac{12}{7}\left(e^{d(S x, B y)}-1\right) \\
& \leq \frac{12}{7}\left(e^{m(x, y)}-1\right) \\
& =2\left(e^{m(x, y)}-1\right)-\frac{2}{7}\left(e^{m(x, y)}-1\right) \\
& =\psi\left(\int_{0}^{m(x, y)} \phi(t) d t\right) \\
& -\varphi\left(\int_{0}^{m(x, y)} \phi(t) d t\right) .
\end{aligned}
$$

This shows that (13) holds.
Finally, in the case (v), we obtain $d(A x, B y)=1$ and $m(x, y)=16$. Now we have

$$
\begin{aligned}
\psi\left(\int_{0}^{d(A x, B y)} \phi(t) d t\right) & =\psi\left(\int_{0}^{1} e^{t} d t\right) \\
& =\psi(e-1) \\
& =2(e-1) \\
& \leq \frac{12}{7}\left(e^{16}-1\right) \\
& =2\left(e^{16}-1\right)-\frac{2}{7}\left(e^{16}-1\right) \\
& =\psi\left(\int_{0}^{16} e^{t} d t\right)-\varphi\left(\int_{0}^{16} e^{t} d t\right) \\
& =\psi\left(\int_{0}^{m(x, y)} \phi(t) d t\right) \\
& -\varphi\left(\int_{0}^{m(x, y)} \phi(t) d t\right) ;
\end{aligned}
$$

that is, the contractive condition (13) holds.

Hence, all the conditions of Theorem 9 are satisfied and 2 is a unique common fixed point of the pairs $(A, S)$ and $(B, T)$ which also remains a point of coincidence as well. Here, one may notice that all the involved mappings are discontinuous at their unique common fixed point 2.

Corollary 11. Let $(X, d)$ be a symmetric space wherein $d$ satisfies the condition $(C C)$ whereas $Y$ is an arbitrary nonempty set with $A, B, S, T: Y \rightarrow X$ satisfying all the hypotheses of Lemma 8. Then $(A, S)$ and $(B, T)$ have a coincidence point each. Moreover, if $Y=X$, then $A, B, S$ and $T$ have a unique common fixed point provided both the pairs $(A, S)$ and $(B, T)$ are weakly compatible.

Proof. Owing to Lemma 8 , it follows that the pairs $(A, S)$ and $(B, T)$ enjoy the $\left(\mathrm{CLR}_{S T}\right)$ property. Hence, all the conditions of Theorem 9 are satisfied, and $A, B, S$ and $T$ have a unique common fixed point provided both the pairs $(A, S)$ and $(B, T)$ are weakly compatible.

Remark 12. The conclusions of Lemma 8, Theorem 9, and Corollary 11 remain true if we choose $m(x, y)=$ $\max M_{A, B, S, T}^{4}(x, y)$ or $m(x, y)=\max M_{A, B, S, T}^{3}(x, y)$.

Our next result shows the importance of common limit range property over common property (E.A).

Theorem 13. Let $(X, d)$ be a symmetric space wherein $d$ satisfies the conditions $(1 C)$ and $(H E)$ whereas $Y$ is an arbitrary nonempty set with $A, B, S, T: Y \rightarrow X$, which satisfy the inequalities (13) and (15) of Lemma 8. Suppose that

(1) the pairs $(A, S)$ and $(B, T)$ satisfy the common property (E.A),

(2) $S(Y)$ and $T(Y)$ are closed subsets of $X$. 
Then $(A, S)$ and $(B, T)$ have a coincidence point each. Moreover, if $Y=X$, then $A, B, S$ and $T$ have a unique common fixed point provided both the pairs $(A, S)$ and $(B, T)$ are weakly compatible.

Proof. Since the pairs $(A, S)$ and $(B, T)$ satisfy the common property (E.A), there exist two sequences $\left\{x_{n}\right\}$ and $\left\{y_{n}\right\}$ in $Y$ such that

$$
\begin{aligned}
\lim _{n \rightarrow \infty} d\left(A x_{n}, z\right) & =\lim _{n \rightarrow \infty} d\left(S x_{n}, z\right)=\lim _{n \rightarrow \infty} d\left(B y_{n}, z\right) \\
& =\lim _{n \rightarrow \infty} d\left(T y_{n}, z\right)=0,
\end{aligned}
$$

for some $z \in X$. Since $S(Y)$ and $T(Y)$ are closed subsets of $X$, therefore $z \in S(Y) \cap T(Y)$. Since $z \in S(Y)$, there exists a point $w \in Y$ such that $S w=z$. Also, since $z \in T(Y)$, there exists a point $v \in X$ such that $T v=z$. The rest of the proof runs on the lines of the proof of Theorem 9.

Remark 14. The conclusions of Theorem 13 remain true if condition (2) of Theorem 13 is replaced by one of the following conditions:

$(2)^{\prime} \overline{A(Y)} \subset T(Y)$ and $\overline{B(Y)} \subset S(Y)$, where $\overline{A(Y)}$ and $\overline{B(Y)}$ denote the closure of ranges of the mappings $A$ and $B$,

$(2)^{\prime \prime} A(Y)$ and $B(Y)$ are closed subsets of $X$ provided $A(Y) \subset T(Y)$ and $B(Y) \subset S(Y)$.

By setting $A, B, S$ and $T$ suitably, we can deduce corollaries involving two and three self-mappings. As a sample, we can deduce the following corollary involving two self-mappings.

Corollary 15. Let $(X, d)$ be a symmetric space wherein $d$ satisfies the conditions $(1 C)$ and $(H E)$ whereas $Y$ is an arbitrary nonempty set with $A, S: Y \rightarrow X$. Suppose that

(1) the pair $(A, S)$ satisfies the $\left(C L R_{S}\right)$ property,

(2) there exist $\varphi \in \Phi$ and $\psi \in \Psi$ such that, for all $x, y \in Y$, we have

$$
\begin{aligned}
& \psi\left(\int_{0}^{d(A x, A y)} \phi(t) d t\right) \\
& \quad \leq \psi\left(\int_{0}^{m(x, y)} \phi(t) d t\right)-\varphi\left(\int_{0}^{m(x, y)} \phi(t) d t\right)
\end{aligned}
$$

where $m(x, y)=\max M_{A, S}^{k}(x, y), k \in\{3,4,5\}$, and $\phi:$ $[0,+\infty) \rightarrow[0,+\infty)$ is a Lebesgue-integrable mapping which is summable and nonnegative such that (15) holds.

Then $(A, S)$ has a coincidence point. Moreover, if $Y=X$, then $A$ and $S$ have a unique common fixed point in $X$ provided the pair $(A, S)$ is weakly compatible.

As an application of Theorem 9, we have the following result involving four finite families of self-mappings.

Theorem 16. Let $(X, d)$ be a symmetric space wherein $d$ satisfies the conditions $(1 C)$ and $(H E)$ whereas $Y$ is an arbitrary nonempty set with $\left\{A_{i}\right\}_{i=1}^{m},\left\{B_{j}\right\}_{j=1}^{n},\left\{S_{r}\right\}_{r=1}^{p},\left\{T_{l}\right\}_{l=1}^{q}: Y \rightarrow$
$X$ satisfying the inequalities (13) and (15) of Lemma 8 where $A=A_{1} A_{2} \cdots A_{m}, B=B_{1} B_{2} \cdots B_{n}, S=S_{1} S_{2} \cdots S_{p}$ and $T=T_{1} T_{2} \cdots T_{q}$. Suppose that the pairs $(A, S)$ and $(B, T)$ satisfy the $\left(C L R_{S T}\right)$ property. Then $(A, S)$ and $(B, T)$ have a point of coincidence each.

Moreover, if $Y=X$, then $\left\{A_{i}\right\}_{i=1}^{m},\left\{B_{j}\right\}_{j=1}^{n},\left\{S_{r}\right\}_{r=1}^{p}$, and $\left\{T_{l}\right\}_{l=1}^{q}$ have a unique common fixed point provided the families $\left(\left\{A_{i}\right\},\left\{S_{r}\right\}\right)$ and $\left(\left\{B_{j}\right\},\left\{T_{l}\right\}\right)$ commute pairwise where $i \in$ $\{1,2, \ldots, m\}, r \in\{1,2, \ldots, p\}, j \in\{1,2, \ldots, n\}$, and $l \in$ $\{1,2, \ldots, q\}$.

Now, we indicate that Theorem 16 can be utilized to derive common fixed point theorems for any finite number of mappings. As a sample, we can derive a common fixed point theorem for six mappings by setting two families of two members while setting the rest two of single members.

Corollary 17. Let $(X, d)$ be a symmetric space wherein $d$ satisfies the conditions $(1 C)$ and $(H E)$ whereas $Y$ is an arbitrary nonempty set with $A, B, H, R, S, T: Y \rightarrow X$. Suppose that

(1) the pairs $(A, S R)$ and $(B, T H)$ share the $\left(C L R_{(S R)(T H)}\right)$ property,

(2) there exist $\varphi \in \Phi$ and $\psi \in \Psi$ such that, for all $x, y \in Y$, we have

$$
\begin{aligned}
& \psi\left(\int_{0}^{d(A x, B y)} \phi(t) d t\right) \\
& \quad \leq \psi\left(\int_{0}^{m(x, y)} \phi(t)\right)-\varphi\left(\int_{0}^{m(x, y)} \phi(t) d t\right),
\end{aligned}
$$

where $m(x, y)=\max M_{A, B, H, R, S, T}^{k}(x, y), k \in\{3,4,5\}$, and $\phi$ : $[0,+\infty) \rightarrow[0,+\infty)$ is a Lebesgue-integrable mapping which is summable and nonnegative such that (15) holds.

Then $(A, S R)$ and $(B, T H)$ have a coincidence point each. Moreover, if $Y=X$, then $A, B, H, R, S$ and $T$ have a unique common fixed point provided $A S=S A, A R=R A, S R=R S$, $B T=T B, B H=H B$, and $T H=H T$.

By setting $A_{1}=A_{2}=\cdots=A_{m}=A, B_{1}=B_{2}=\cdots=$ $B_{n}=B, S_{1}=S_{2}=\cdots=S_{p}=S$, and $T_{1}=T_{2}=\cdots=T_{q}=T$ in Theorem 16, one gets the following corollary.

Corollary 18. Let $(X, d)$ be a symmetric space wherein $d$ satisfies the conditions $(1 C)$ and $(H E)$ whereas $Y$ is an arbitrary nonempty set with $A, B, S, T: Y \rightarrow X$. Suppose that

(1) the pairs $\left(A^{m}, S^{p}\right)$ and $\left(B^{n}, T^{q}\right)$ share the $\left(C L R_{\left(S^{p} T^{q}\right)}\right)$ property, where $m, n, p, q$ are fixed positive integers,

(2) there exist $\varphi \in \Phi$ and $\psi \in \Psi$ such that, for all $x, y \in Y$, we have

$$
\begin{aligned}
& \psi\left(\int_{0}^{d\left(A^{m} x, B^{n} y\right)} \phi(t) d t\right) \\
& \quad \leq \psi\left(\int_{0}^{m(x, y)} \phi(t) d t\right)-\varphi\left(\int_{0}^{m(x, y)} \phi(t) d t\right),
\end{aligned}
$$


where $m(x, y)=\max M_{A^{m}, B^{n}, S^{p}, T^{q}}^{k}(x, y), k \in\{3,4,5\}$, and $\phi:$ $[0,+\infty) \rightarrow[0,+\infty)$ is a Lebesgue-integrable mapping which is summable and nonnegative such that (15) holds.

Moreover, if $Y=X$, then $A, B, S$ and $T$ have a unique common fixed point provided $A S=S A$ and $B T=T B$.

Remark 19. The above Corollary 18 is a slight but partial generalization of Theorem 9 as the commutativity requirements (i.e., $A S=S A$ and $B T=T B$ ) in this corollary are relatively stronger as compared to weak compatibility in Theorem 9.

\section{Conflict of Interests}

The authors declare that there is no conflict of interests regarding the publication of this paper.

\section{Acknowledgment}

The first author gratefully acknowledges the support from the Deanship of Scientific Research (DSR) at King Abdulaziz University (KAU) during this research.

\section{References}

[1] T. L. Hicks and B. E. Rhoades, "Fixed point theory in symmetric spaces with applications to probabilistic spaces," Nonlinear Analysis A: Theory and Methods, vol. 36, no. 3, pp. 331-344, 1999.

[2] R. P. Pant, "Noncompatible mappings and common fixed points," Soochow Journal of Mathematics, vol. 26, no. 1, pp. 29$35,2000$.

[3] G. Jungck, "Compatible mappings and common fixed points," International Journal of Mathematics and Mathematical Sciences, vol. 9, no. 4, pp. 771-779, 1986.

[4] S. Sessa, "On a weak commutativity condition of mappings in fixed point considerations," Institut Mathématique, vol. 32(46), pp. 149-153, 1982.

[5] G. Jungck and B. E. Rhoades, "Fixed points for set valued functions without continuity," Indian Journal of Pure and Applied Mathematics, vol. 29, no. 3, pp. 227-238, 1998.

[6] S. L. Singh and A. Tomar, "Weaker forms of commuting maps and existence of fixed points," Journal of the Korea Society of Mathematical Education B, vol. 10, no. 3, pp. 145-161, 2003.

[7] P. P. Murthy, "Important tools and possible applications of metric fixed point theory," Nonlinear Analysis: Theory, Methods \& Applications, vol. 47, no. 53479, 3490 pages, 2001.

[8] M. A. Al-Thagafi and N. Shahzad, "Generalized I-nonexpansive selfmaps and invariant approximations," Acta Mathematica Sinica, vol. 24, no. 5, pp. 867-876, 2008.

[9] M. Abbas and B. E. Rhoades, "Common fixed point theorems for occasionally weakly compatible mappings satisfying a generalized contractive condition," Mathematical Communications, vol. 13, no. 2, pp. 295-301, 2008.

[10] A. Aliouche and V. Popa, "Common fixed point theorems for occasionally weakly compatible mappings via implicit relations," Filomat, vol. 22, no. 2, pp. 99-107, 2008.

[11] A. Bhatt, H. Chandra, and D. R. Sahu, "Common fixed point theorems for occasionally weakly compatible mappings under relaxed conditions," Nonlinear Analysis A: Theory and Methods, vol. 73, no. 1, pp. 176-182, 2010.
[12] M. Imdad, S. Chauhan, Z. Kadelburg, and C. Vetro, "Fixed point theorems for non-self mappings in symmetric spaces under $\varphi$ weak contractive conditions and an application to functional equations in dynamic programming," Applied Mathematics and Computation, vol. 227, pp. 469-479, 2014.

[13] D. Đorić, Z. Kadelburg, and S. Radenović, "A note on occasionally weakly compatible mappings and common fixed points," Fixed Point Theory, vol. 13, no. 2, pp. 475-479, 2012.

[14] M. Aamri and D. El Moutawakil, "Some new common fixed point theorems under strict contractive conditions," Journal of Mathematical Analysis and Applications, vol. 270, no. 1, pp. 181188, 2002.

[15] K. P. R. Sastry and I. S. R. Krishna Murthy, "Common fixed points of two partially commuting tangential selfmaps on a metric space," Journal of Mathematical Analysis and Applications, vol. 250, no. 2, pp. 731-734, 2000.

[16] Y. Liu, J. Wu, and Z. Li, "Common fixed points of single-valued and multivalued maps," International Journal of Mathematics and Mathematical Sciences, no. 19, pp. 3045-3055, 2005.

[17] M. Imdad, S. Chauhan, and Z. Kadelburg, "Fixed point theorem for mappings with common limit range property satisfying generalized $(\psi, \varphi)$-weak contractive conditions," Mathematical Sciences, vol. 7, article 16, 2013.

[18] A. H. Soliman, M. Imdad, and M. Hasan, "Proving unified common fixed point theorems via common property (E.A) in symmetric spaces," Korean Mathematical Society, vol. 25, no. 4, pp. 629-645, 2010.

[19] R. P. Pant, "Common fixed points of Lipschitz type mapping pairs," Journal of Mathematical Analysis and Applications, vol. 240, no. 1, pp. 280-283, 1999.

[20] W. Sintunavarat and P. Kumam, "Common fixed point theorems for a pair of weakly compatible mappings in fuzzy metric spaces," Journal of Applied Mathematics, vol. 2011, Article ID 637958, 14 pages, 2011.

[21] M. Imdad, B. D. Pant, and S. Chauhan, "Fixed point theorems in Menger spaces using the $\left(C L R_{S T}\right)$ property and applications," Journal of Nonlinear Analysis and Optimization: Theory and Applications, vol. 3, no. 2, pp. 225-237, 2012.

[22] E. Karapınar, D. K. Patel, M. Imdad, and D. Gopal, "Some nonunique common fixed point theorems in symmetric spaces through $C L R_{(S, T)}$ property," International Journal of Mathematics and Mathematical Sciences, Article ID 753965, 8 pages, 2013.

[23] D. Gopal, R. P. Pant, and A. S. Ranadive, "Common fixed point of absorbing maps," Bulletin Marathwada Mathematical Society, vol. 9, no. 1, pp. 43-48, 2008.

[24] Ya. I. Alber and S. Guerre-Delabriere, "Principle of weakly contractive maps in Hilbert spaces," in New Results in Operator Theory and its Applications, vol. 98 of Operator Theory: Advances and Applications, pp. 7-22, 1997.

[25] B. E. Rhoades, "Some theorems on weakly contractive maps," Nonlinear Analysis, vol. 47, pp. 2683-2693, 2001.

[26] A. Branciari, "A fixed point theorem for mappings satisfying a general contractive condition of integral type," International Journal of Mathematics and Mathematical Sciences, vol. 29, no. 9, pp. 531-536, 2002.

[27] A. Djoudi and A. Aliouche, "Common fixed point theorems of Gregus type for weakly compatible mappings satisfying contractive conditions of integral type," Journal of Mathematical Analysis and Applications, vol. 329, no. 1, pp. 31-45, 2007.

[28] Z. Liu, X. Li, S. M. Kang, and S. Y. Cho, "Fixed point theorems for mappings satisfying contractive conditions of integral type 
and applications," Fixed Point Theory and Applications, vol. 64, article 18, 2011.

[29] B. Samet and C. Vetro, "An integral version of Ćirićs fixed point theorem," Mediterranean Journal of Mathematics, vol. 9, no. 1, pp. 225-238, 2012.

[30] W. Sintunavarat and P. Kumam, "Gregus-type common fixed point theorems for tangential multivalued mappings of integral type in metric spaces," International Journal of Mathematics and Mathematical Sciences, vol. 2011, Article ID 923458, 12 pages, 2011.

[31] W. Sintunavarat and P. Kumam, "Gregus type fixed points for a tangential multi-valued mappings satisfying contractive conditions of integral type," Journal of Inequalities and Applications, vol. 2011, article 3, 2011.

[32] T. Suzuki, "Meir-Keeler contractions of integral type are still Meir-Keeler contractions," International Journal of Mathematics and Mathematical Sciences, vol. 2007, Article ID 39281, 6 pages, 2007.

[33] C. Vetro, S. Chauhan, E. Karapnar, and W. Shatanawi, "Fixed points of weakly compatible mappings satisfying generalized $\varphi$-weak contractions," Bulletin of the Malaysian Mathematical Sciences Society. In press.

[34] Q. Zhang and Y. Song, "Fixed point theory for generalized $\varphi$ weak contractions," Applied Mathematics Letters, vol. 22, no. 1, pp. 75-78, 2009.

[35] D. Đorić, "Common fixed point for generalized $(\psi, \varphi)$-weak contractions," Applied Mathematics Letters, vol. 22, no. 12, pp. 1896-1900, 2009.

[36] P. N. Dutta and B. S. Choudhury, "A generalisation of contraction principle in metric spaces," Fixed Point Theory and Applications, Article ID 406368, 8 pages, 2008.

[37] M. Imdad, J. Ali, and M. Tanveer, "Coincidence and common fixed point theorems for nonlinear contractions in Menger PM spaces," Chaos, Solitons \& Fractals, vol. 42, no. 5, pp. 3121-3129, 2009.

[38] S. Radenović, Z. Kadelburg, D. Jandrlić, and A. Jandrlić, "Some results on weakly contractive maps," Iranian Mathematical Society: Bulletin, vol. 38, no. 3, pp. 625-645, 2012.

[39] W. A. Wilson, "On semi-metric spaces," American Journal of Mathematics, vol. 53, no. 2, pp. 361-373, 1931.

[40] A. Aliouche, "A common fixed point theorem for weakly compatible mappings in symmetric spaces satisfying a contractive condition of integral type," Journal of Mathematical Analysis and Applications, vol. 322, no. 2, pp. 796-802, 2006.

[41] F. Galvin and S. D. Shore, "Completeness in semimetric spaces," Pacific Journal of Mathematics, vol. 113, no. 1, pp. 67-75, 1984.

[42] S.-H. Cho, G.-Y. Lee, and J.-S. Bae, "On coincidence and fixedpoint theorems in symmetric spaces," Fixed Point Theory and Applications, Article ID 562130, 9 pages, 2008.

[43] M. Aamri and D. El Moutawakil, "Common fixed points under contractive conditions in symmetric spaces," Applied Mathematics E-Notes, vol. 3, pp. 156-162, 2003.

[44] D. Gopal, M. Hasan, and M. Imdad, "Absorbing pairs facilitating common fixed point theorems for Lipschitzian type mappings in symmetric spaces," Korean Mathematical Society: Communications, vol. 27, no. 2, pp. 385-397, 2012.

[45] D. Gopal, M. Imdad, and C. Vetro, "Common fixed point theorems for mappings satisfying common property (E.A.) in symmetric spaces," Filomat, vol. 25, no. 2, pp. 59-78, 2011.

[46] M. Imdad and J. Ali, "Common fixed point theorems in symmetric spaces employing a new implicit function and common property (E.A)," Bulletin of the Belgian Mathematical Society, vol. 16, no. 3, pp. 421-433, 2009.

[47] M. Imdad, J. Ali, and L. Khan, "Coincidence and fixed points in symmetric spaces under strict contractions," Journal of Mathematical Analysis and Applications, vol. 320, no. 1, pp. 352360, 2006.

[48] D. Turkoglu and I. Altun, "A common fixed point theorem for weakly compatible mappings in symmetric spaces satisfying an implicit relation," Sociedad Matemática Mexicana, vol. 13, no. 1, pp. 195-205, 2007.

[49] M. Imdad, A. Sharma, Chauhan, and S. :, "Unifying a multitude of metrical fixed point theorems in symmetric spaces," Filomat. In press. 


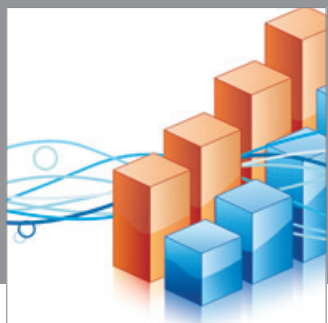

Advances in

Operations Research

mansans

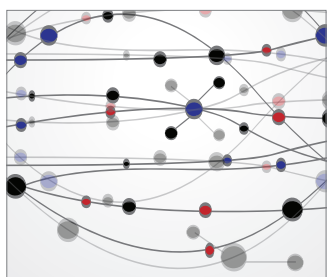

The Scientific World Journal
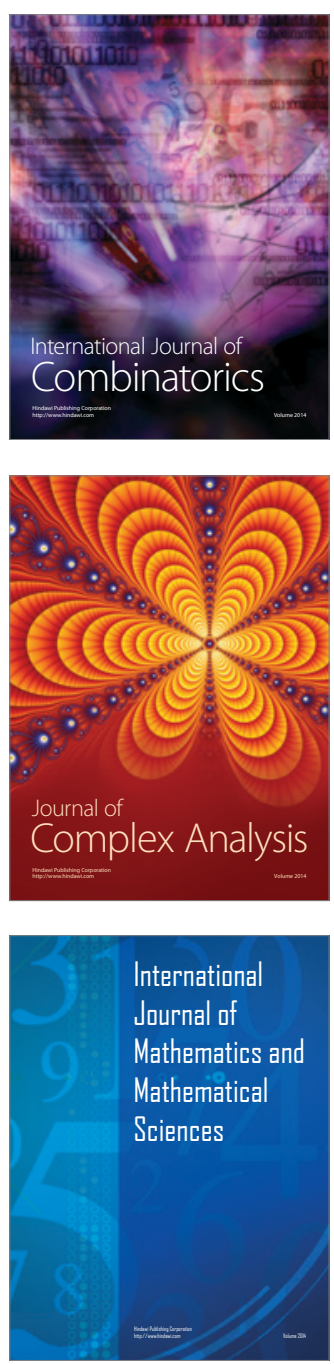
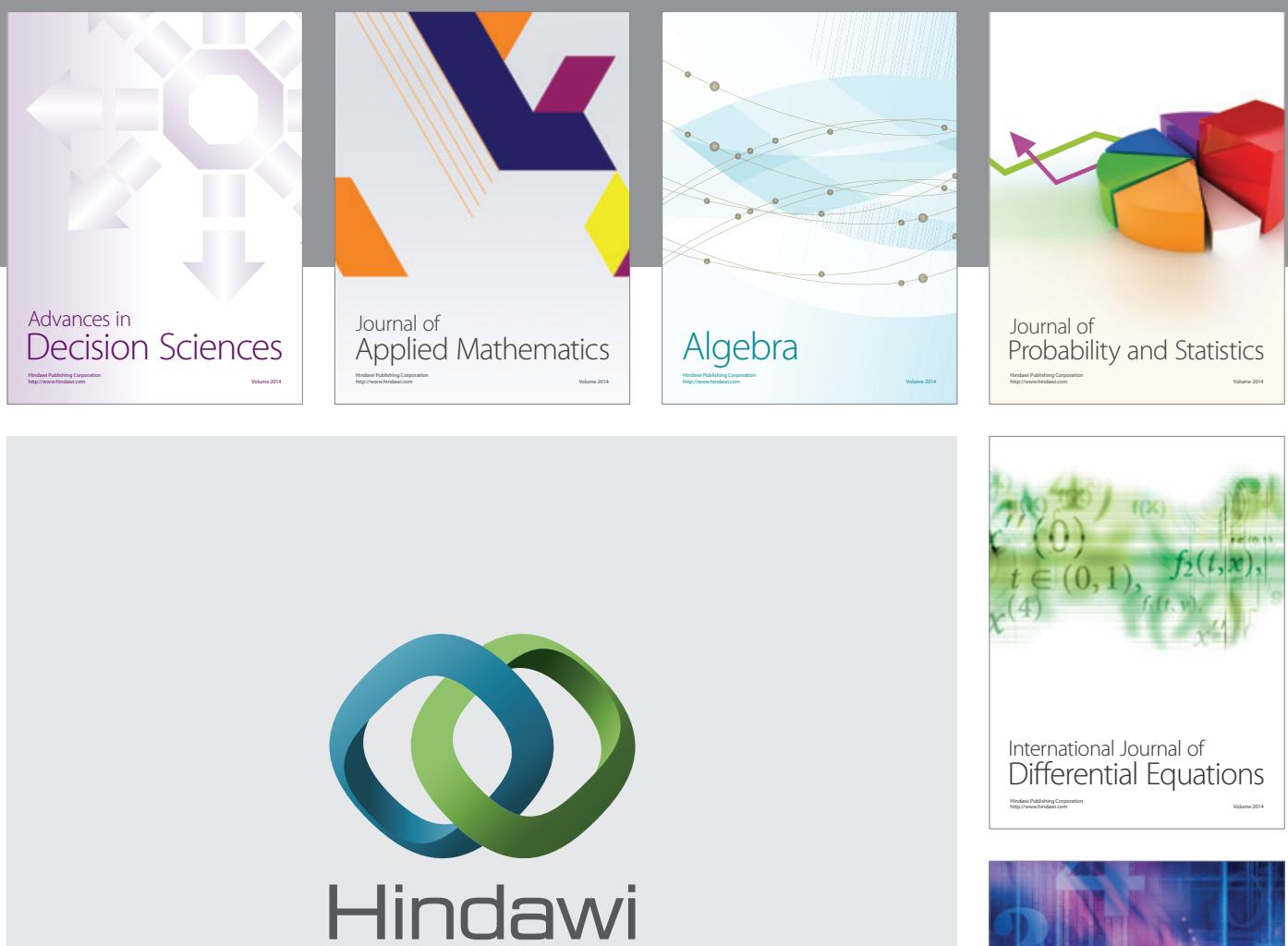

Submit your manuscripts at http://www.hindawi.com
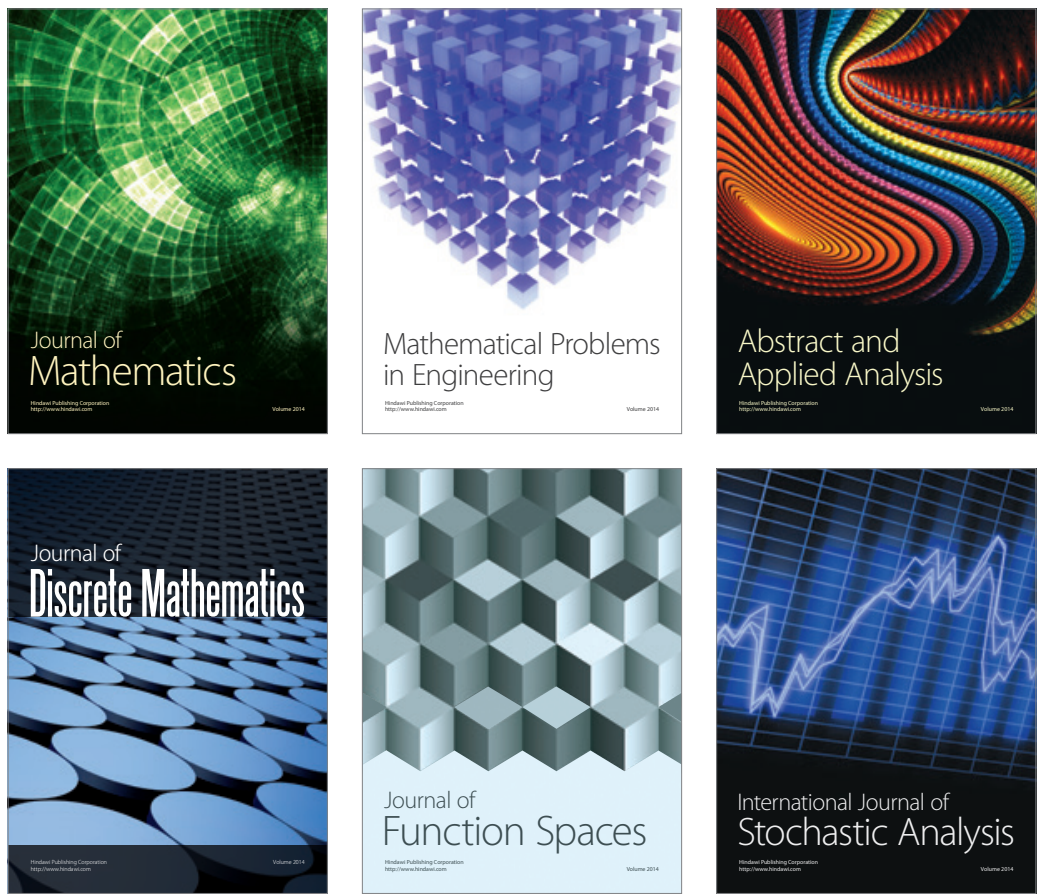

Journal of

Function Spaces

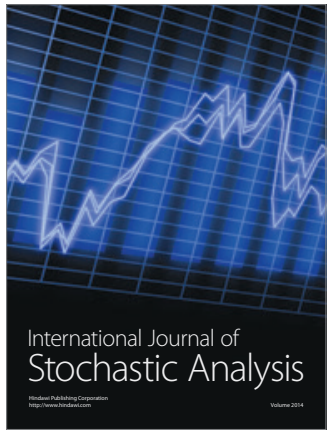

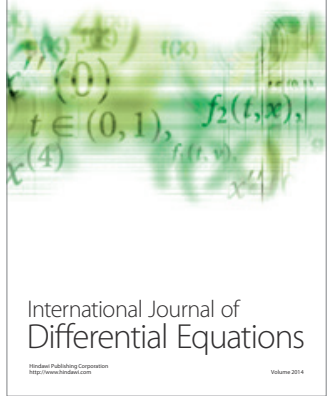
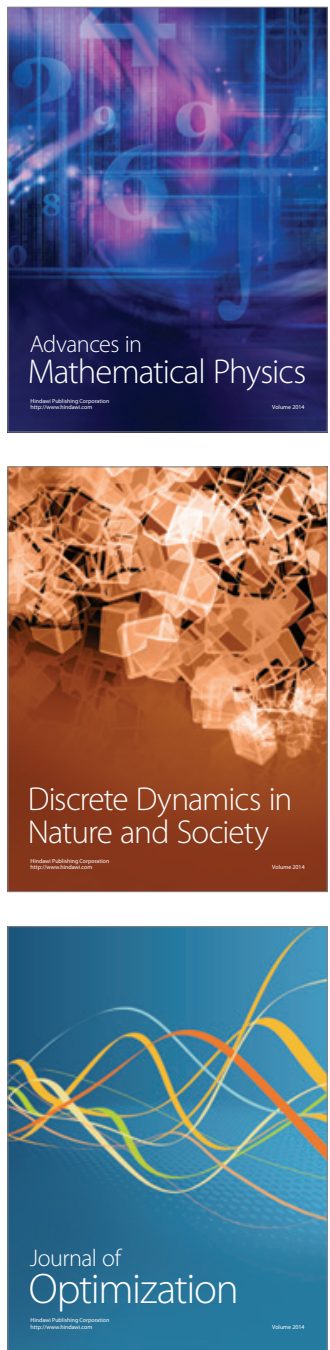